\title{
LAS CAUSALES DE ANULACIÓN DEL LAUDO ARBITRAL EN LA LEY DE ARBITRAJE DEL PERÚ
}

\author{
Mario Castillo Freyre \\ Rita Sabroso Minaya* \\ Laura Castro Zapata \\ Jhoel Chipana Catalán ${ }^{* * *+*}$
}

Recibido: 29.09 .2014

Aprobado: 19.10.2014

\section{Resumen}

En el presente artículo, los autores analizan los alcances de todas las causales de anulación de laudo reguladas por la vigente Ley de Arbitraje del Perú. Asimismo, hacen referencia a una serie de supuestos no contemplados en dicha ley, exponiendo sus puntos de vista en relación a cada uno de ellos.

\section{Palabras clave}

Arbitraje - Nulidad - Laudo - Internacional - Deliberación.

\begin{abstract} to each of them.

Key Words

Arbitration - Invalidity - Award - International - Deliberation.
\end{abstract}

In this article, the authors discuss the implications of all grounds for annulment of an arbitration award stipulated by the Arbitration Act of Peru. They also refer to a number of cases not covered by that law, stating their views in relation

\section{INTRODUCCIÓN}

Al igual que en el ámbito judicial, todo proceso arbitral implica la existencia de una relación jurídica compuesta por las partes del arbitraje que decidieron, por medio de un conve- nio arbitral, someter su conflicto de intereses a dicho proceso.

Dentro de este esquema, la característica más significativa del arbitraje es, sin lugar a dudas, la importancia que posee la autonomía privada. En ese senti- do, la autonomía privada de las partes, constituye el eje central de todo arbitraje, pues es a partir de esa autonomía que se desarrolla la «justicia privada».

Sin embargo, frente a ese resultado final del proceso arbitral

* Magíster y Doctor en Derecho, Abogado en ejercicio, socio del Estudio que lleva su nombre; profesor principal de Obligaciones y Contratos en la Pontificia Universidad Católica del Perú y en la Universidad Femenina del Sagrado Corazón. Catedrático de las mismas materias en la Universidad de Lima. Miembro de Número de la Academia Peruana de Derecho. Director de las colecciones Biblioteca de Arbitraje y Biblioteca de Derecho de su Estudio. www. castillofreyre.com.

** Abogada por la Pontificia Universidad Católica del Perú. Profesora de Obligaciones y de Arbitrajes Especiales en la PUCP y en la Universidad de Lima, respectivamente. Con estudios en la Maestría de Derecho de la Competencia y Propiedad Intelectual en la Pontificia Universidad Católica del Perú. Miembro del Área de Arbitraje del Estudio Mario Castillo Freyre.

*** Abogada por la Universidad Femenina del Sagrado Corazón. Magíster en Derecho, con mención en Derecho Empresarial, por la Universidad de Lima. Ha concluido sus estudios en el Doctorado en Derecho de la Pontificia Universidad Católica del Perú. Dirige el área corporativa del Estudio Mario Castillo Freyre y también se desempeña como Árbitro.

${ }^{* * * *}$ Abogado por la Pontificia Universidad Católica del Perú, Profesor Adjunto en la misma casa de estudios, Abogado en el Estudio Mario Castillo Freyre y Secretario Arbitral en procesos Ad-hoc. 
que se materializa en un laudo, existen figuras que se pueden invocar para intentar anularlo.

Es a esas figuras a las que nos referiremos en este ensayo.

\section{Causales de anulación del LAUDO}

La vigente Ley de Arbitraje del Perú regula en su artículo 63 una serie de causales por las que un laudo puede ser declarado nulo.

El inciso 1, literal a), del artículo 63 de la Ley de Arbitraje, establece que el laudo sólo podrá ser anulado cuando la parte que solicita la anulación alegue y pruebe que el convenio arbitral es inexistente, nulo, anulable, inválido o ineficaz.

El literal a) señala de manera expresa una causal de anulación no prevista anteriornente. Dicha causal está referida a la posibilidad de interponer recurso de anulación contra un laudo cuando el convenio arbitral sea inexistente, nulo, anulable, ineficaz o inválido.

La derogada Ley General de Arbitraje, Ley N. ${ }^{\circ} 26572$, sólo contemplaba el supuesto de nulidad del convenio arbitral, por lo que la nueva Ley de Arbitraje abre la puerta a la posibilidad de anular el laudo cuando el convenio arbitral también sea inexistente, anulable, ineficaz o inválido.

Sobre el particular, Cantuarias Salaverry ${ }^{2}$ se pregunta cuándo un convenio arbitral es nulo y, citando a Lohmann, señala que lo es cuando se encuentra incurso en alguno de los supuestos del artículo 219 del Código Civil o en otra norma.

Asimismo, Cantuarias señala que la opinión de Lohmann es lógica y obvia, ya que si se alega y prueba que el convenio arbitral se encuentra incurso en al-

Artículo 63.- Causales de anulación

1. El laudo sólo podrá ser anulado cuando la parte que solicita la anulación alegue y pruebe:

a. Que el convenio arbitral es inexistente, nulo, anulable, inválido o ineficaz.

b. Que una de las partes no ha sido debidamente notificada del nombramiento de un árbitro o de las actuaciones arbitrales, o no ha podido por cualquier otra razón, hacer valer sus derechos.

c. Que la composición del tribunal arbitral o las actuaciones arbitrales no se han ajustado al acuerdo entre las partes o al reglamento arbitral aplicable, salvo que dicho acuerdo o disposición estuvieran en conflicto con una disposición de este Decreto Legislativo de la que las partes no pudieran apartarse, o en defecto de dicho acuerdo o reglamento, que no se han ajustado a lo establecido en este Decreto Legislativo.

d. Que el tribunal arbitral ha resuelto sobre materias no sometidas a su decisión.

e. Que el tribunal arbitral ha resuelto sobre materias que, de acuerdo a ley, son manifiestamente no susceptibles de arbitraje, tratándose de un arbitraje nacional.

f. Que según las leyes de la República, el objeto de la controversia no es susceptible de arbitraje o el laudo es contrario al orden público internacional, tratándose de un arbitraje internacional.

g. Que la controversia ha sido decidida fuera del plazo pactado por las partes, previsto en el reglamento arbitral aplicable o establecido por el tribunal arbitral.

2. Las causales previstas en los incisos $a, b, c$ y d del apartado 1 de este artículo sólo serán procedentes si fueron objeto de reclamo expreso en su momento ante el tribunal arbitral por la parte afectada y fueron desestimadas.

3. Tratándose de las causales previstas en los incisos d) y e) del apartado 1 de este artículo, la anulación afectará solamente a las materias no sometidas a arbitraje o no susceptibles de arbitraje, siempre que puedan separarse de las demás; en caso contrario, la anulación será total. Asimismo, la causal prevista en el inciso e) podrá ser apreciada de oficio por la Corte Superior que conoce del recurso de anulación.

4. La causal prevista en el inciso g) del apartado 1 de este artículo sólo será procedente si la parte afectada lo hubiera manifestado por escrito de manera inequívoca al tribunal arbitral y su comportamiento en las actuaciones arbitrales posteriores no sea incompatible con este reclamo.

5. En el arbitraje internacional, la causal prevista en el inciso a) del apartado 1 de este artículo se apreciará de acuerdo con las normas jurídicas elegidas por las partes para regir el convenio arbitral, por las normas jurídicas aplicables al fondo de la controversia, o por el derecho peruano, lo que resulte más favorable a la validez y eficacia del convenio arbitral.

6. En el arbitraje internacional, la causal prevista en el inciso f) podrá ser apreciada de oficio por la Corte Superior que conoce del recurso de anulación.

7. No procede la anulación del laudo si la causal que se invoca ha podido ser subsanada mediante rectificación, interpretación, integración o exclusión del laudo y la parte interesada no cumplió con solicitarlos.

8. Cuando ninguna de las partes en el arbitraje sea de nacionalidad peruana o tenga su domicilio, residencia habitual o lugar de actividades principales en territorio peruano, se podrá acordar expresamente la renuncia al recurso de anulación o la limitación de dicho recurso a una o más causales establecidas en este artículo. Si las partes han hecho renuncia al recurso de anulación y el laudo se pretende ejecutar en territorio peruano, será de aplicación lo previsto en el título VIII.

2 Cantuarias Salaverry, Fernando. «Anulación de un laudo arbitral por la causal de nulidad del convenio arbitral». En Revista Iberoamericana de Arbitraje y Mediación. http://www.servilex.com.pe/arbitraje/colaboraciones/anullaudo.html. 
guna causal de nulidad del acto jurídico, éste y el laudo arbitral deberían ser declarados nulos por el Poder Judicial.

Por otro lado, debemos tener presente que el literal a) del inciso 1 del artículo 65 de la Ley de Arbitraje establece que si el laudo se anula por esta causal, la materia que fue objeto de arbitraje podrá ser demandada judicialmente, salvo acuerdo distinto de las partes.

En efecto, generado un conflicto, «A» inicia el arbitraje contra «B»y logra un laudo a su favor, ante lo cual «B» interpone recurso de anulación basado en la causal de nulidad del convenio arbitral, que es amparado por el Poder Judicial. ¿La controversia tendrá que someterse al Poder Judicial? La respuesta es que sí, porque la anulación del laudo arbitral se debió al hecho que no existía entre las partes un convenio arbitral, por lo que no cabe la menor duda de que la competencia del Poder Judicial se restablecerá para resolver cualquier controversia existente entre las partes, salvo que suscriban válidamente un acuerdo de arbitraje. ${ }^{3}$

Finalmente, debemos precisar que esta causal sólo será proce- dente si fue objeto de reclamo expreso en su momento ante el tribunal arbitral por la parte afectada y el mismo fue desestimado. ${ }^{4}$

En efecto, es lógico que los reparos sobre la existencia, ineficacia o invalidez del convenio arbitral sean expresados desde un inicio en el mismo proceso arbitral y desde el inicio también hayan sido desatendidos por los árbitros. Lo que el sentido común expresado en la Ley quiere es que el reclamo sobre algo tan grave sea oportuno dentro del mismo proceso y no interesado cuando se perdió el proceso. $\mathrm{Si}$ los árbitros tuvieron razón o no en desatender el reclamo inicial de las partes, lo resolverá la jurisdicción ordinaria una vez terminado el proceso arbitral. ${ }^{5}$

En segundo término, el literal b) del artículo bajo estudio estipula que el laudo sólo podrá ser anulado cuando la parte que solicita la anulación alegue y pruebe que una de las partes no ha sido debidamente notificada del nombramiento de un árbitro o de las actuaciones arbitrales, 0 no ha podido por cualquier otra razón, hacer valer sus derechos.

En relación a la causal regulada por el literal b), Cantuarias ${ }^{6}$ señala que esta causal de anulación debe ser alegada y probada por quien la invoca y tiene por misión salvaguardar el debido proceso y el derecho de defensa de las partes.

Así, comenzaremos por señalar que el concepto de debido proceso fue desarrollado a partir del Derecho estadounidense.

Carocca ${ }^{7}$ sostiene que los orígenes históricos de la noción de debido proceso en el Common Law, nos revelan que se trata de una fórmula sustancialmente amplia, indeterminada, que busca la justicia en la tramitación de un concreto proceso. Su importancia radica en que se asienta en el principio esencial de la tradición jurídica anglosajona conforme al cual where there is no remedy there is no right, en el sentido de que el derecho existe en cuanto se lo une en judictio persequi a través del ejercicio de un form of action.

La garantía del debido proceso ha venido a transformarse, con el andar del tiempo, en el símbolo de la garantía jurisdiccional en sí misma.

Por su parte, la Constitución peruana de 1993 tiene el mérito de

Idem.

4 Recordemos que el inciso 1 del artículo 41 de la Ley de Arbitraje establece que «el tribunal arbitral es el único competente para decidir sobre su propia competencia, incluso sobre las excepciones u objeciones al arbitraje relativas a la inexistencia, nulidad, anulabilidad, invalidez o ineficacia del convenio arbitral o por no estar pactado el arbitraje para resolver la materia controvertida o cualesquiera otras cuya estimación impida entrar en el fondo de la controversia. Se encuentran comprendidas en este ámbito las excepciones por prescripción, caducidad, cosa juzgada y cualquier otra que tenga por objeto impedir la continuación de las actuaciones arbitrales». (El subrayado es nuestro).

5 Castillo Freyre, Mario y Ricardo Vásquez Kunze (2006) Arbitraje. El Juicio Privado: la verdadera reforma de la Justicia. Biblioteca de Arbitraje del Estudio Mario Castillo Freyre. Vol. 1. Lima: Palestra Editores-Estudio Mario Castillo Freyre, p. 257.

6 Cantuarias Salaverry, Fernando (2004). «Anulación de un Laudo Arbitral por la causal de violación del debido proceso y el derecho de defensa». En: Arbitraje On Line. Lima: Centro de Conciliación y Arbitraje Nacional e Internacional de la Cámara de Comercio de Lima, año II, n. ${ }^{\circ}$, septiembre 2004, p. 1. En http://www.camaralima.org.pe/arbitraje/boletín/ edic ant/3/voz arbitro2.htm.

7 Carocca Pérez, Alex (1997). «Las Garantías Constitucionales del Debido Proceso y de la Tutela Judicial Efectiva en España». En: Revista Jurídica del Perú. Trujillo: Editora Normas Legales, año XIV, n. ํ 2, p. 85. 
invocar expresamente la observancia del debido proceso como un criterio de obligatorio cumplimiento. Ello lo hace dentro de un artículo dedicado a los llamados «Principios y derechos de la función jurisdiccional», precepto en el cual -a su vez- se incluyen una serie de elementos habitualmente asumidos como componentes centrales de todo debido proceso que presuma de serlo.

Tal como señala De Bernardis, ${ }^{8}$ resulta en extremo importante que se haya otorgado al debido proceso rango constitucional, en la medida que permite establecer con carácter absoluto su aplicación en cualquier proceso que se pretenda llevar a cabo, ante cualquier persona o autoridad pues, por su carácter fundamental, requiere de una interpretación amplia que le permita estar presente para hacer posible alcanzar el mayor grado de justicia.

El debido proceso es el cumplimiento de todas las garantías del orden público, que deben aplicarse en todos los procesos. Dentro de tal orden de ideas, la violación del debido proceso -siempre y cuando se haya reclamado ésta en su oportunidad y haya perjudicado ostensiblemente los derechos procesales del reclamante-, es también una causal de anulación del laudo. Se entiende aquí también por violación del debido proceso la indebida notificación de la designación de un árbitro. Los efectos que la Ley quiere para esta anulación son los de preferir pese a todo el arbitraje, que el arbitraje no muera sino que despierte nuevamente a la vida desembarazado de la violación y sus consecuencias, preservando todo lo actuado en el proceso hasta antes de la violación, para, a partir de allí, continuar con el arbitraje y llegar a un laudo fruto del respeto al debido proceso. ${ }^{9}$

Aquí también debemos precisar que esta causal sólo será procedente si fue objeto de reclamo expreso en su momento ante el tribunal arbitral por la parte afectada y el mismo fue desestimado.

Finalmente, debemos tener presente que el literal $b$ ) del inciso 1 del artículo 65 de la Ley de Arbitraje, establece que si el laudo se anula por esta causal, el tribunal arbitral debe reiniciar el arbitraje desde el momento en que se cometió la violación manifiesta del derecho de defensa.

A su turno, el literal c) señala que el laudo sólo podrá ser anulado cuando la parte que solicita la anulación alegue y pruebe que la composición del tribunal arbitral o las actuaciones arbitrales no se han ajustado al acuerdo entre las partes o al reglamento arbitral aplicable, salvo que dicho acuerdo o disposición estuvieran en conflicto con una disposición de este Decreto Legislativo de la que las partes no pudieran apartarse, o en defecto de dicho acuerdo o regla- mento, que no se han ajustado a lo establecido en este Decreto Legislativo.

La Ley de Arbitraje peruana, como la mayoría de las leyes arbitrales que basan de manera correcta su articulado en el respeto a la autonomía de la voluntad, deja a las partes y, en su defecto, a los árbitros, un amplio margen para construir el procedimiento arbitral que mejor se acomode a sus intereses. Justamente, con la finalidad de salvaguardar esta libertad, la causal bajo comentario autoriza la anulación del laudo arbitral, cuando la composición del tribunal o el procedimiento no se han ajustado al acuerdo de las partes, siempre y cuando las disposiciones contractuales no se opongan a las normas imperativas de la propia Ley de Arbitraje. $^{10}$

El oportuno reclamo dentro del mismo proceso arbitral resulta aquí también condición para que esta causal prospere. El efecto de la anulación del laudo por esta causal es, obviamente, el que las partes procedan a un nuevo nombramiento de árbitros o, en su caso, el tribunal arbitral deba reiniciar el arbitraje en el estado en el que no se observó el acuerdo de las partes, el reglamento o la norma aplicable, de conformidad con lo establecido por el literal c) del inciso 1 del artículo 65 de la Ley de Arbitraje.

El literal d) regula el supuesto de que el tribunal se haya pro-

8 De Bernardis, Luis Marcelo (1995). La garantía procesal del debido proceso. Lima: Cultural Cuzco Editores, pp. 413 y 414.

9 Castillo Freyre, Mario y Ricardo Vásquez Kunze (2006). Arbitraje. El Juicio Privado: la verdadera reforma de la Justicia. Vol. 1. Biblioteca de Arbitraje del Estudio Mario Castillo Freyre. Lima: Palestra Editores-Estudio Mario Castillo Freyre, p. 258.

10 Cfr. Cantuarias Salaverry, Fernando (2007). Arbitraje Comercial y de las Inversiones. Lima: UPC, pp. 484-485. 
nunciado sobre materias no sometidas a su decisión, es decir, haber laudado extra petita.

Como bien sabemos, los árbitros sólo pueden resolver sobre cuestiones que hayan sido pactadas en el convenio arbitral o en acto posterior.

Lete $^{11}$ señala que no resultaría factible que los árbitros decidieran resolver cuestiones ajenas a la materia para la que fueron nombrados, pues ello se encontraría en flagrante contradicción con el propio fundamento de la institución arbitral.

Tal como señala Barona, ${ }^{12}$ el fin de la anulación por esta causal es dejar sin efecto lo que constituye exceso en el laudo, pero no corregir sus deficiencias $y$ omisiones, sin posibilidad -por tanto- de discutir el mayor o menor fundamento de lo resuelto, reduciéndose a examinar si hubo o no exceso jurisdiccional, traspasando los límites objetivos del compromiso.

Por otro lado, Cantuarias ${ }^{13}$ precisa que la anulación sólo afectará los puntos no sometidos a decisión, siempre y cuando tengan sustantividad propia y no aparezcan inseparablemente unidos a la cuestión principal. Además, debe tenerse en cuenta que la causal bajo comentario sólo afectará a los laudos ar- bitrales que contengan excesos en la materia (extra petita o ultra petita), pero no cuando los árbitros hayan fallado omitiendo resolver sobre alguna materia sometida a su conocimiento (infra petita).

En la misma línea encontramos a Palacios, ${ }^{14}$ quien sostiene, en relación con la hipótesis de que el recurso de nulidad sea favorablemente acogido por el hecho de haberse dictado el laudo sobre puntos no controvertidos, que se autoriza a declarar la nulidad parcial del pronunciamiento, si éste es divisible.

A entender de Munné, ${ }^{15}$ en este supuesto puede solicitarse y, en su caso, declararse tan sólo la anulación parcial del laudo, en la medida que la materia no sometida a decisión del árbitro sea escindible de las cuestiones sometidas a su conocimiento y sobre las que no se declara su anulación. En caso contrario, debería declararse la anulación de todas esas cuestiones, las cuales deberán plantearse de forma conjunta en un proceso ordinario posterior.

El hecho que se haya laudado sobre algo que no se ha pedido es, obviamente, una causal de anulación del laudo. Aquí, quiere la Ley que la anulación afecte el laudo sólo en aquello que está de más por la razón que fuere, mientras se le pueda separar fácilmente de lo que sí se pidió que se laudara. Si no se puede separar, porque una cosa es indesligable de la otra, no procede la anulación. ${ }^{16}$

Al igual que en los casos anteriores, esta causal sólo será procedente si fue objeto de reclamo expreso en su momento ante el tribunal arbitral por la parte afectada y el mismo fue desestimado.

Finalmente, debemos tener presente que el literal d) del inciso 1 del artículo 65 de la Ley de Arbitraje establece que si el laudo se anula por esta causal, la materia no sometida a arbitraje podrá ser objeto de un nuevo arbitraje, si estuviera contemplada en el convenio arbitral. En caso contrario, la materia podrá ser demandada judicialmente, salvo acuerdo distinto de las partes.

El literal e) indica que el laudo sólo podrá ser anulado cuando la parte que solicita la anulación alegue y pruebe que el tribunal arbitral ha resuelto sobre materias que, de acuerdo a ley, son manifiestamente no susceptibles de arbitraje, tratándose de un arbitraje nacional.

En este caso se está haciendo alusión a las exclusiones señaladas en el artículo 2 de la Ley,

11 Lete Achirica, Javier (2004) . «Acción de anulación del laudo» En: Comentarios prácticos a la Ley de Arbitraje. Valladolid: Editorial Lex Nova S.A., p. 658.

12 Citada por Cantuarias Salaverry, Fernando (2005). «Anulación de un laudo arbitral por la causal de exceso en la resolución de la materia sometida a arbitraje». En: Ius et Veritas. N. ${ }^{\circ}$ 30. Lima: Revista editada por alumnos de la Facultad de Derecho de la Pontificia Universidad Católica del Perú, p. 204.

13 Cantuarias Salaverry, Fernando. «Anulación de un laudo arbitral por la causal de exceso en la resolución de la materia sometida a arbitraje». Op. cit., p. 208.

14 Citado por Ledesma Narváez, Marianella (2002). «Laudos arbitrales y medios impugnatorios» En: Cuadernos Jurisprudenciales. N. ${ }^{\circ}$ 17, Lima: Gaceta Jurídica, noviembre 2002, p. 24.

15 Munné Catarina, Frederic (2004). El arbitraje en la Ley N. ${ }^{\circ}$ 60/2003. Barcelona: Ediciones Experiencia S.L., 2004 , p. 180.

16 Castillo Freyre, Mario y Ricardo Vásquez Kunze (2006). Arbitraje. El Juicio Privado: la verdadera reforma de la Justicia. Op. cit., p. 260. 
que son las excepciones en lo que respecta a materias no arbitrables (las reguladas en el artículo 1).

El artículo 1 de la Ley establece que pueden someterse a arbitraje las controversias sobre materias de libre disposición, conforme a Derecho, así como aquéllas que la ley, los tratados o acuerdos internacionales autoricen.

De otro lado, el literal f) del inciso 1 del artículo 63 de la Ley, señala que el laudo sólo podrá ser anulado cuando la parte que solicite la anulación alegue y pruebe que, según las leyes de la República, el objeto de la controversia no es susceptible de arbitraje o el laudo es contrario al orden público internacional, tratándose de un arbitraje internacional.

Esto también va de la mano con lo señalado en el artículo 2, especialmente, en el inciso $2 .{ }^{17}$

Y, por último, el laudo podrá ser anulado cuando, según lo dispuesto en el literal g) del inciso 1 , la controversia ha sido decidida fuera del plazo pactado por las partes, previsto en el reglamento arbitral aplicable o establecido por el tribunal arbitral.

Los plazos para laudar -que siempre deben encontrarse pactados en el acta de instalación del tribunal arbitral o fijados supletoriamente por la ley o el reglamento que resultare aplicable al proceso- son muy im- portantes y su incumplimiento puede determinar, a diferencia de lo que ocurre con las sentencias judiciales, la anulación del laudo.

Aquí, anulado el laudo por esta causal, puede iniciarse un nuevo arbitraje, salvo que las partes acuerden componer un nuevo tribunal arbitral para que sobre la base de las actuaciones resuelva la controversia o, tratándose de arbitraje nacional, dentro de los quince días siguientes de notificada la resolución que anula el laudo, decidan por acuerdo, que la Corte Superior que conoció del recurso de anulación resuelva en única instancia sobre el fondo de la controversia, de conformidad con lo establecido por el literal f) del inciso 1 del artículo 65 de la Ley de Arbitraje.

\section{ANÁlISIS DE LOS INCISOS 2 A 8 DEL ARTíCULO 63 DE LA LEY DE ARBITRAJE}

El inciso 2 del artículo 63 señala que las causales previstas en los literales a), b), c) y d) del numeral 1 de dicho artículo, sólo serán procedentes si fueran objeto de reclamo expreso en su momento ante el tribunal arbitral por la parte afectada y tales reclamos fueron desestimados.

Básicamente, de lo que se trata es que las partes no se guarden causales de nulidad bajo la manga.

Si uno conociera, en general, de alguna de estas causales que afectara el propio derecho, pues tiene que expresarlo de inmediato, vía la impugnación del acto del tribunal arbitral. Es decir, de acuerdo a ley, tratándose de actos o resoluciones distintas al laudo, lo único que procede es el recurso de reconsideración.

Ni siquiera procede la anulación del laudo cuando se denuncia la existencia de una causal y no se interpone recurso de reconsideración, precisamente, sobre la resolución del tribunal arbitral. Ello, porque no se ha dado la oportunidad para que el tribunal revise su decisión y enmiende esa situación irregular que, eventualmente, se estaría denunciando por parte de quien se considere afectado por ella.

Esto, naturalmente, a menos que el tribunal arbitral no haya permitido la interposición del respectivo recurso de anulación, como podría ser el caso en que hubiese laudado estando pendiente de vencimiento el plazo para la interposición de un recurso.

En estos casos, entendemos que bastará que la parte afectada deje constancia de la irregularidad cometida.

El inciso 3 del artículo 63 de la Ley señala que tratándose de las causales previstas en los incisos d) y e) del numeral 1 de este artículo, la anulación afectará solamente a las materias no sometidas a arbitraje o no susceptibles de arbitraje, siempre que puedan separarse de las demás.

17 Artículo 2.- Materias susceptibles de arbitraje

1. Pueden someterse a arbitraje las controversias sobre materias de libre disposición conforme a derecho, así como aquellas que la ley o los tratados o acuerdos internacionales autoricen.

2. Cuando el arbitraje sea internacional y una de las partes sea un Estado o una sociedad, organización o empresa controlada por un Estado, esa parte no podrá invocar las prerrogativas de su propio derecho para sustraerse a las obligaciones derivadas del convenio arbitral. 
Lo señalado en este numeral es importante, en la medida que el literal d) se refiere al laudo que haya resuelto extra petita y el literal e), a que el tribunal arbitral haya resuelto sobre materias que no son susceptibles de arbitraje, es decir, materias que están reservadas a los tribunales ordinarios.

En esos casos, la norma favorece la estabilidad del laudo arbitral, en la medida en que se ha seguido un proceso y hay que tratar de preservar lo ahí resuelto; naturalmente, separando aquella parte del laudo que se pronuncie sobre materias no controvertidas o que sean de orden público.

Aquí se sigue la regla general establecida por el Código Civil en materia de acto jurídico, que se asimila de alguna manera a la Ley de Arbitraje, de acuerdo a la norma que estamos comentando, en el sentido de que las nulidades que afectan algunas disposiciones del acto jurídico, no tienen por qué extenderse a todo el acto, en la medida en que dichas disposiciones nulas sean separables. En materia del laudo arbitral, ocurre algo similar.

La parte del laudo que pueda haber resuelto extra petita, o la parte del laudo que haya resuelto sobre materias no susceptibles de arbitraje será anulada, sin perjuicio de aquellas otras partes del laudo que permanecerán como válidas.

En un caso como éste, esa separación perfecta podría determinar que la controversia concluya allí, y que se preserve la solidez del laudo. En todo caso, las otras materias podrán ser objeto de otros arbitrajes, en caso ellas se puedan someter a arbitraje de acuerdo al convenio arbitral y a la ley; o a algún reclamo en los tribunales ordinarios, en caso se haya anulado la materia cuyo conocimiento era vetado por la ley para los tribunales arbitrales.

Todo esto podrá realizarse en la medida de lo señalado por el propio inciso 3 del artículo 63, es decir, siempre que esos extremos del laudo puedan separarse de los demás.

Habrá casos en los cuales eso resultará imposible, en la medida en que no resulte clara la diferencia en materia de tratamiento, consideraciones y, sobre todo, en la parte resolutiva, entre las materias arbitrables y las materias no arbitrables.

En esos casos, la anulación, como señala el inciso 3 del artículo 63 , será total.

Es importante lo que se señala en la última parte de esta norma, cuando se agrega que del mismo modo la causal prevista en el literal e) podrá ser apreciada de oficio por la Corte Superior que conoce del recurso de anulación.

Ello, por cuanto, como recordamos, este literal e), precisamente, se refiere a aquellos supuestos de anulación en los cuales el tribunal arbitral hubiese resuelto sobre materias que de acuerdo a ley son manifiestamente no susceptibles de arbitraje, tratándose de un arbitraje nacional. 0 sea, en estos casos, a pesar de que no constituya materia pretendida en la anulación, el tribunal ordinario que conoce el asunto podrá de- clarar la nulidad del laudo o del extremo respectivo del laudo, conforme a lo expuesto en el propio inciso 3 del artículo 64 de la Ley.

Por otra parte, el inciso 4 señala que la causal prevista en el literal $\mathrm{g}$ ) del numeral 1 de este artículo, sólo será procedente si la parte afectada lo hubiera manifestado por escrito de manera inequívoca al tribunal arbitral, y su comportamiento en las actuaciones arbitrales posteriores no sea incompatible con este reclamo.

Es decir, el literal g) es el que establece la causal de anulación, en caso la controversia hubiere sido decidida fuera del plazo pactado por las partes, previsto en el Reglamento Arbitral aplicable o establecido por el tribunal arbitral. Dice este literal que, en estos casos, sólo procederá la anulación, si la parte lo hubiera manifestado por escrito de manera inequívoca al tribunal. La Ley de Arbitraje vigente (Decreto Legislativo N. ${ }^{\circ}$ 1071) no ha señalado, como lo hacía la Ley anterior, que esta comunicación se efectúe antes de notificado el laudo.

Tal vez se haya considerado inútil esta mención porque aquí básicamente lo que se quiere es precisar si se dejó constancia del vencimiento del plazo.

En ese sentido, bastará con que se hubiere manifestado por escrito de manera inequívoca al tribunal arbitral, y su comportamiento en las actuaciones arbitrales posteriores no sea incompatible con este reclamo.

Pero aquí ya se genera un problema, porque bastará con 
mencionar la posición de la parte, en el sentido de considerar que el plazo para el trámite del arbitraje o el plazo para laudar ya hubiera vencido. Pero, ¿qué pasará si lo dijo una vez y no lo repite? Pues, en virtud de lo dispuesto por la segunda parte del inciso 4 del artículo 63, alguien -equivocadamente- podría considerar que está consintiendo y que luego no se puede retractar de sus actos propios. Justamente esa mención podría conducir -de modo innecesario- a que la parte que ha dejado constancia del vencimiento del plazo para laudar, sea hostil en todas las actuaciones posteriores.

Éste es un grave error de la norma, pues podría dar lugar a la errónea interpretación de que condene a esa parte a una situación de hostilidad y a la frustración o dilación innecesaria de todas las actuaciones ulteriores, en donde ella tendría que reiterar su posición en el sentido de que el plazo para laudar ha vencido, a efectos de que no se pueda interpretar de ninguna manera que su comportamiento posterior en las actuaciones arbitrales pudiese ser entendido como una declinación de ese reclamo.

En ese sentido, consideramos deficiente la redacción de esta norma.

Creemos, por lo demás, que bastaría con haber señalado esto en un escrito y que el comportamiento posterior de la parte, desarrollando las actuaciones arbitrales y no obstaculizando el fin del proceso, no deberá tomarse como un asentimiento. De ninguna manera podría interpretarse esto como una posibilidad de aplicar la teoría de los actos propios, en la medida en que ya se hubiese señalado expresamente cuál es la posición al respecto y -obviamente- no tendría por qué ser reiterada. Es decir, debe seguir las actuaciones, pero ya señaló que el plazo para laudar ha vencido.

Por lo demás, ¿qué otra solución habría que no sea que el tribunal llegue a concluir con las actuaciones arbitrales y luego se pueda proceder a la anulación?

El tribunal no puede dejar abandonado el arbitraje. Eso es imposible. Y más aún, eso resulta complicado cuando, seguramente -como debe ocurrir en casos como éstos-, existe controversia sobre el vencimiento del plazo, con lo cual la otra parte podrá argumentar lo que estime conveniente al respecto, y la parte que se considere afectada por el eventual vencimiento del plazo recurra ante los tribunales ordinarios para solicitar eventualmente la anulación del laudo.

En conclusión, esta segunda parte del inciso 4 del artículo 63 de la Ley, es impertinente.

A su turno, el inciso 5 del artículo 63, señala que en el arbitraje internacional, la causal prevista en el inciso a) del numeral 1 de este artículo se apreciará de acuerdo con las normas jurídicas elegidas por las partes para regir el convenio arbitral, por las normas jurídicas aplicables al fondo de la controversia, o por el derecho peruano, lo que resulte más favorable a la validez y eficacia del convenio arbitral.
Y es que en el literal a) del inciso 1 del artículo 63 se hace referencia a que el convenio arbitral es inexistente, nulo, anulable, inválido o ineficaz. Lo que ocurre es que estos términos, que son propios de la legislación civil peruana, no necesariamente van a tener una correspondencia exacta en la legislación civil extranjera, conforme a las leyes aplicables por las partes en el arbitraje internacional.

Por esa razón es que en el inciso 5 del artículo 63 de la Ley, se establece que esta causal se apreciará de acuerdo con las normas jurídicas elegidas por las partes para regir el convenio arbitral.

Eso será importantísimo. Y luego se dice: «por las normas jurídicas aplicables al fondo de la controversia», es decir, las normas del país cuya legislación sustantiva se va a aplicar al proceso o el Derecho peruano, supletoriamente, lo que resulte más favorable a la validez del convenio arbitral.

Aquí no se establece una relación de subsidiariedad ni de supletoriedad. Acá se está aplicando un criterio en torno a cuál es la norma más favorable para la validez y eficacia del convenio arbitral.

Complicado asunto, porque no necesariamente ésta es una solución adecuada, donde se ingresa a un criterio de valoración normativa. Y este criterio de valoración normativa es uno muy susceptible de interpretación.

Hubiese sido preferible, en lugar de aplicar el principio favorable a la conservación o a la validez del arbitraje o del convenio arbitral, establecer un orden pre- 
latorio; establecer que serán aplicables las normas legales que rijan el convenio arbitral; o establecer que serán aplicables las normas que rijan el fondo de la controversia, de acuerdo a lo acordado por las partes; o establecer que regirán las normas establecidas en el Derecho peruano sobre el particular.

Ninguno de estos tres eventuales caminos, si es que se hubiesen adoptado definitivos, alteraría las consideraciones sobre estos temas, y daría una solución muy clara para la solución de la controversia.

Pensamos que en lugar de aplicar el principio favorable al arbitraje, aquí hubiese sido preferible aplicar un principio favorable a una interpretación racional del tema y no dejarlo a una incertidumbre jurídica, que es precisamente aquélla que se percibe en la redacción del inciso 5 del artículo 63.

El inciso 6 del artículo 63 señala que en el arbitraje internacional, la causal prevista en el inciso f) podrá ser apreciada de oficio por la Corte Superior que conoce del recurso de anulación.

Como se recuerda, la causal mencionada se basa en que, según las leyes de la República, el objeto de la controversia no sea susceptible de arbitraje, o el laudo sea contrario al orden público internacional, tratándose de un arbitraje internacional.

Acá se sigue precisamente la tesis, muy arraigada en el Derecho peruano y ratificada por la legislación civil en el Código de 1984 y en los precedentes, que en casos de nulidades manifiestas, como sería el de la contra- vención señalada en estas normas, de preceptos o normas de orden público, los tribunales de justicia podrán declarar la nulidad de oficio.

En estos casos se está recogiendo en el inciso 6 del artículo 63 de la Ley de Arbitraje, este mismo principio, el cual resulta de aplicación general en el Derecho peruano.

El inciso 7 del artículo 63 señala que no procede la anulación del laudo si la causal que se invoca ha podido ser subsanada mediante rectificación, interpretación, integración o exclusión del laudo y la parte interesada no cumplió con solicitarlo.

Esto resulta fundamental porque, precisamente, todas las facultades y los recursos que se conceden a las partes en el artículo 58 de la Ley, que es el precepto que recoge todos estos recursos, están destinados a que las partes puedan hacer que el tribunal arbitral corrija algún error, omisión, exceso o falta de claridad en que hubiera incurrido.

De no hacer efectivos estos derechos, se entiende que la parte está conforme con el laudo, y no se puede volver sobre aquello en donde ya se manifestó conformidad.

Esto, además, va de la mano con todos los principios que recoge la Ley de Arbitraje, en el sentido de que cualquier causal de anulación pasa, precisamente, por haber hecho ejercicio del reclamo respectivo con respecto a las resoluciones generales (vale decir, haber interpuesto recurso de reconsideración), y con respecto al laudo (haber interpuesto definitivamente los recursos de rectificación, interpretación, integración o exclusión), cuya resolución hubiese podido salvar el reclamo que luego se interponga y que determinará, precisamente, la improcedencia de dicho reclamo.

Finalmente, el inciso 8 del artículo 63 de la Ley señala que cuando ninguna de las partes en el arbitraje sea de nacionalidad peruana o tenga su domicilio, residencia habitual o lugar de actividades principales en territorio peruano, se podrá acordar expresamente la renuncia al recurso de anulación o la limitación de dicho recurso a una o más causales establecidas en este artículo. Si las partes han hecho renuncia al recurso de anulación y el laudo se pretende ejecutar en territorio peruano, será de aplicación lo previsto en el Título VIII de la Ley de Arbitraje.

Ahora bien, el artículo 63, inciso 8 , debe ser visto con mucho cuidado. Entendemos que aquí lo que se está facilitando es la posibilidad de que los extranjeros que encuentren como sede o que elijan como sede del arbitraje, el territorio de la República del Perú, puedan disponer de esta manera para que el laudo arbitral tenga la mayor solidez y se eviten ulteriores reclamos en torno a la decisión del tribunal arbitral que resolvió la controversia.

Sin embargo, acá viene una pregunta fundamental y es la relativa a si debe el Derecho permitir a las partes que por convenio o por contrato hagan tabla rasa de aquellos principios fundamentales del debido proceso que, precisamente, están 
recogidos en la propia Ley de Arbitraje.

Es decir, ¿se puede renunciar por anticipado a ejercer un derecho, en virtud de lo establecido por el propio inciso 8 del artículo 63 de la Ley de Arbitraje?

Aquí cabe, evidentemente, una consideración que a nuestro juicio es importante. Ella se basa en el hecho que existen normas como ésta, que para algunos pueden ser consideradas simplemente como actos de disposición de derechos sustantivos y que para otros, como es el caso de quienes escribimos estas páginas, pueden considerarse como renuncia a derechos irrenunciables.

El Derecho no puede auspiciar renuncias anticipadas a que los tribunales arbitrales se rijan por criterios de rectitud y apego a las normas y principios del Derecho Procesal.

En estos casos es evidente que una norma de estas características no debería prosperar, de tal manera que debería darse trámite, debería admitirse un recurso de anulación que, eventualmente, parta por desdecirse de aquello pactado en virtud del inciso 8 del artículo 63. $Y$ si el mismo fuese desestimado, creemos que es perfectamente factible que la parte que se considere perjudicada pueda recurrir al amparo ante los tribunales ordinarios, por cuanto los derechos constitucionales y el debido proceso son irrenunciables en el territorio de la República del Perú y una norma como ésta no puede vulnerarlos.
Creemos que el inciso 8 del artículo 63 es abiertamente inconstitucional, porque las normas de orden público del territorio de la República del Perú no sólo se aplican a los peruanos, sino también a los extranjeros que tienen relación con nuestro territorio; y la Ley de Arbitraje sí resulta aplicable, precisamente, porque las partes la han escogido dentro de un marco constitucional al cual no pueden renunciar: la Constitución de la República del Perú.

Juan Luis Avendaño ${ }^{18}$ señala, sobre este punto, que el pacto de exclusión de recurso de anulación está previsto únicamente para el arbitraje internacional y dentro de las situaciones que analiza el inciso octavo del artículo 63. Por el contrario, en el caso de arbitrajes nacionales no es posible tal pacto, porque sería renunciar a un derecho contemplado en nuestra legislación y que es de orden público. El recurso de anulación es una garantía de legalidad irrenunciable que tienen todos los que se someten a la jurisdicción arbitral.

\section{Supuestos de anUlación no CONTEMPLADOS EN LA LEY DE AR- BITRAJE}

Finalmente, queremos criticar que no se haya incluido como causal de anulación del laudo la posibilidad de impugnarlo por haberse laudado sin las mayorías requeridas, como sí lo hacía la derogada Ley General de Arbitraje. $^{19}$

En los supuestos en donde hemos señalado la no existencia de un laudo, es decir, aquéllos en los cuales sólo voten los dos árbitros de parte en sentidos opuestos, aquél otro en el cual sólo vote un árbitro de parte (caso indudable de no existencia de un laudo) y el último supuesto -de solución discutible- en donde sólo votó el presidente, la Ley no establece una solución expresa al problema.

Por un lado, podría entenderse que al no haber habido laudo, cualquiera de las partes estaría facultada para dar inicio a un nuevo proceso arbitral.

Similar razonamiento podría esgrimirse para el caso en el cual ninguno de los tres árbitros hubiese laudado.

¿Pero qué ocurriría en aquel supuesto en el que una de las partes señale que a pesar de existir el solo voto del presidente y al no haber sido impugnada dicha decisión, la misma deba considerarse firme $y$, por tanto, deba estimarse que tal voto tiene la categoría jurídica de laudo?

Recordemos, el por todos conocido inciso 4 del artículo 73 de la derogada Ley General de Arbitraje, Ley N. ${ }^{\circ} 26572$, que establecía como una de las causales de anulación, el haber laudado sin las mayorías requeridas.

Y ¿cuál es el correlato de esta norma en la actual Ley de Arbitraje?

Pues, simplemente, no existe correlato alguno, vale decir que no se ha contemplado entre las nuevas causales de anulación de

18 Avendaño Valdez, Juan Luis. «Causales de anulación». En AA.VV. Comentarios a la ley peruana de arbitraje. Op. cit., tomo I, p. 718.

19 En efecto, el inciso 4 del artículo 73 de la Ley General de Arbitraje contemplaba dicha posibilidad. 
los laudos arbitrales, el caso en el cual el tribunal hubiese laudado sin contar con las mayorías requeridas.

Dudamos mucho de que puedan hacerse extensivos los alcances del literal c) del inciso 1 del artículo 63 de la nueva Ley, cuando señala como una de las causales de anulación de los laudos, el que las actuaciones arbitrales no se hubieren ajustado a lo dispuesto por el Decreto Legislativo N. 1071.

Decimos esto, en la medida que la decisión de aquel árbitro que en solitario emitió su voto -en principio-, no transgrediría ninguna disposición ni de la Ley de Arbitraje ni, eventualmente, del Reglamento arbitral que resultare aplicable o de la respectiva acta de instalación.

Queremos subrayar que el voto en cuestión sería un voto emitido plenamente dentro de los cauces jurídicos, de modo tal que ese voto no se apartaría de ninguna disposición legal ni reglamentaria.

Esto significa que nos encontraríamos ante un vacío de la Ley que no debió producirse, habida cuenta de que el artículo 52 de la Ley de Arbitraje no llega a cerrar un círculo en el que pueda decirse que siempre habrá una decisión arbitral, ya que es evidente que en algunos casos como los expuestos, simplemente no habrá laudo.

Debemos admitir que si sólo hubiese votado un árbitro de parte, se podría sostener que al no haberse laudado por mayoría, se estaría contraviniendo una disposición de la propia Ley (el artículo 52, inciso 1 ).
Pero no ocurriría lo mismo en el supuesto en el cual el único que hubiese emitido su voto hubiera sido el presidente del tribunal arbitral, ya que aquí también se podría sostener la no existencia de mayorías; pero, por otra parte, se podría argumentar que el laudo sí fue emitido mayoritariamente, si se entendiera aplicable la ficción contemplada en el inciso 2 del referido artículo 52.

En todo caso, creemos que el artículo 63 hubiese hecho bien en mantener como una de las causales de anulación, la de haber laudado sin las mayorías requeridas; ello, con el propósito que no quede duda alguna de que ésta sigue siendo una causal de anulación de los laudos arbitrales, y de que no se pueda discutir -como lamentablemente sí puede ocurrir ahora- que dicho supuesto debe entenderse como una de las contravenciones previstas en el literal c) del referido artículo 63.

En efecto, hubo reconocidos profesores que consideraron que el inciso 4 del artículo 73 de la derogada Ley General de Arbitraje no tenía efectos prácticos.

Creemos que si bien el artículo 47 de la Ley General de Arbitraje reducía las posibilidades de que no existiera un laudo, consideramos que sí podía presentarse algún supuesto que conllevara la aplicación del inciso 4 del artículo 73 de la derogada Ley. En efecto, pensemos en el caso en el cual el laudo es emitido por un solo árbitro de parte. Aquí cabe preguntarnos ¿qué sucede con los otros dos árbitros (el otro árbitro de parte y el presidente) que no se pronun- ciaron? ¿Se entienden adheridos los otros dos árbitros a lo decidido por el primero?

Cuando dos árbitros emiten el laudo, el tercero -que no se pronunció- se entiende adherido a lo decidido por la mayoría. Sin embargo, si el laudo fue emitido por uno, que no es el presidente, dos no se pueden adherir al voto de uno, porque uno no hace mayoría.

Creemos que éste es un supuesto en el cual se podía demandar la anulación del laudo, en virtud de lo dispuesto por el inciso 4 del artículo 73 de la derogada Ley General de Arbitraje, ya que - sin lugar a dudas - se trataba de un laudo emitido sin las mayorías requeridas.

Otro supuesto podría ser aquél en el cual los dos árbitros de parte no emiten voto alguno y el presidente sí lo hace.

Si bien sabemos que los artículos 46 y 49 de la derogada Ley General de Arbitraje, Ley N. ${ }^{\circ}$ 26572, contemplaban la posibilidad que los árbitros que no han emitido voto se adhieran al de la mayoría, aquí no estamos ante ese supuesto, ya que el solo voto del presidente -lo reiteramos- no hace mayoría y no podría entenderse que los otros dos árbitros se adhirieron a dicho único voto.

Finalmente, un tercer supuesto sería aquél en el cual los árbitros de parte emiten sus votos (uno declara fundada la pretensión y el otro la declara improcedente) y el presidente -que se supone es el que decide- no emite voto alguno y tampoco se designa al árbitro dirimente, tal como lo establecía el segundo 
párrafo del artículo 47 de la derogada Ley.

Aquí no se puede entender que el Presidente se adhiere a los votos de los otros árbitros, en la medida que no hay mayoría a la cual adherirse.

En tal sentido, y no habiéndose designado al árbitro dirimente, ni siquiera se podría hablar de laudo, ya que sólo se tendrían dos votos distintos. Sin embargo, en el supuesto de que alguno o los dos árbitros notifiquen sus votos como laudo, ellos antes, bien podrían haberse anulado en virtud a lo prescrito por el inciso 4 del artículo 73 de la derogada Ley General de Arbitraje.

Dentro de tal orden de ideas, estos tres supuestos señalados también se pueden presentar hoy en día, con la vigente Ley de Arbitraje, por lo que -lo reiteramos- hubiese sido mejor mantener -como una de las causales de anulación- la de haber laudado sin las mayorías requeridas.

\section{A MANERA DE CONCLUSIÓN}

En base a lo expuesto, no podemos sino enfatizar que nuestra legislación tiene una posición clara en torno a la autonomía del arbitraje, de allí que sus normas se orientan a reforzar tal autonomía estableciendo que el fondo de la controversia se resuelve de manera absoluta y definitiva por el tribunal arbitral.

En este esquema, el contenido, los alcances y, más importante aún, la manera en que opera en los hechos el recurso de anulación, resulta extremadamente relevante, puesto que sólo su adecuada aplicación puede garantizar la autonomía, desarrollo y utilidad del arbitraje. 